\title{
A Systematic Review on Open Educational Games for Programming Learning and Teaching
}

\author{
https://doi.org/10.3991/ijet.v15i09.12437 \\ Josivan Pereira da Silva $\left({ }^{\square}\right)$ \\ Mackenzie Presbyterian University, Sao Paulo, Brazil \\ josivan.engenharia@gmail.com \\ Ismar Frango Silveira \\ Mackenzie Presbyterian University, Sao Paulo, Brazil \\ Cruzeiro do Sul University, Sao Paulo, Brazil
}

\begin{abstract}
One of the main barriers for Educational Game (EG) to properly fulfill the specific pedagogical, cultural and technical requirements that are often unique to each situation is the difficulty of reusing and adapting them to different educational contexts. In this sense, open EGs could facilitate reuse and adaptation, once they follow the openness principles. This paper provides a systematic review of Open Educational Games (OEG) designed specifically for teaching computer programming and computational logic. It has been identified that most authors find the issue of reusing and adapting EGs following the openness philosophy as very important, but even them fail to use open tools in game development. We conclude that most articles recommend using component-based development, reuse and adaptation, but reuse still does not happen in a practical sense. Also, the amount of studies on EGs for teaching programming is low in the scientific literature, and most open EGs available on the Internet are not documented nor have some associated published paper. Thus, reuse and adaptation may even occur, but without scientific documentation and publication.
\end{abstract}

Keywords-Open educational games, open educational resources, role-playing game, reuse, adaptation.

\section{Introduction}

In the last decades, we have seen that the Information and Communication Technologies (ICT) could bring valuable tools to help teaching and learning processes, since them allow more interaction and collaboration than traditional communication tools, which could help students to learn in a more efficient way, besides potentially making teaching process easier, expanding some common limits and barriers $[1,2]$.

However, ICT have been proven not being a magical recipe that effectively changed the educational process: new pedagogies and practices are required to explore the potential of ICT in schools. Besides, the complexity of challenges that are 
presented in the contemporary world makes the relationship of teachers and students with ICT to go beyond just using them as tools.

One of the most valuable capacities demanded nowadays are skills related to Computational Thinking, among them the ability to design algorithms and program them in some programming language. Programming is considered by many as one of the abilities of the 21 st century $[3,4]$. It is becoming a commonsense to consider programming skills as important as other fundamental skills, like Math, reading and writing. One of the common job requirements today is computer literacy or fluency, which includes more than basic skills on how to use computer-based technologies or mobile devices; thus, programming definitely a skill that every student must acquire [5].

In contrast with the demand about programming skills is the difficulty to acquire them, due mainly to the high levels of abstraction involved in programming logic, or the need of a constant, always high, level of motivation and real engagement to progress in learning how to code [6,7]. Maybe because of these reasons, there is a trend of decreasing interest in learning Computer Science, although there is opposite trend in job requirements; learning and teaching programming both are often considered hard tasks to be performed, novice programmers quickly lose motivation and give up, and university introductory programming courses have high dropout rates [5].

Many recent studies $[8,9,10,11,12,13,14]$ show positive, but not determinant, results in teaching/learning a formal content with aid of Educational Game (EG). Digital Games (DG) have the potential to help students to understand complex concepts in a more ludic way and could be used as a manner to motivate the student to be more engaged with the learning objectives, making progress in the subject to be learned. According to [39] DGs are not only played, but speaking, read, listen and others characteristics that can help in the learning activities.

However, there are many problems to develop and use EGs that effectively help students to learn in formal education, as the high cost to properly develop them since they involve a multidisciplinary team; the difficulty to integrate game ludic narrative with learning objectives; the uneasiness to make EGs that are fun and didactically effective at the same time; among others difficulties that arise in EG development. $[15,16]$.

One important barrier to use of the EG in classrooms is the difficulty to adapt them to specific contexts and needs. The majority of EGs are not open-source nor they are built under a plug-and-play modular architecture - which would aid to change some game components, it is not easy to guarantee adaptation and reuse $[15,8]$. A move towards the openness principles, together with proper architectural decisions, could make EGs more suitable to adaptation and, consequently, reuse.

In this sense, this paper brings a systematic literature review about Open Educational Games (OEG) that has learning objective the fundamentals of programming logic. 


\section{Background and Related Research}

In this topic, important concepts of OEG foundations are presented.

\subsection{Digital games and educational games}

There are several definitions for DGs and EGs in both past and recent scientific literature, but the majority shows a close relationship between both, being clear that later are a subtype of former.

According to [27] a DG is a rule-based formal system with a variable and quantifiable outcome. Additionally, [28] has the definition of DG as a digital system of rules and objects and it can motivate and guide player decisions to specific goals and subgoals. Another definition for DG is found in [29]: a form of entertainment and media that can provide learning possibilities, which is played in digital devices.

In this sense, [27] affirms that Educational Digital Games are games that provide, to students, the opportunity to reinforce some previous knowledge by repeating it in a more comfortable and ludic environment. Even though the definition of [27] limits the use of EGs to reinforce some already acquired skill, many authors agree with not so limiting definitions; games are usually presented as effective, engaging tools that could support active learning, experimental learning and problem-based learning [30][49].

According to [30], Game-Based Learning (GBL) refers to any kind of learning strategy that makes use of any DG - educational or not - as a way to reach a set of learning objectives. Having this in mind, it is possible that a simple entertainment game to be repurposed with educational goals; however, it becomes more feasible according to the degree of liberty for modifications such a game presents. Since in general EGs are known as "boring" $[15,17]$, the repurposing of pure entertainment games could be a pathway to more engaging, thus more effective, EGs.

\subsection{Open-source software and open educational resources}

Open-source software could be defined as computer programs that have a specific type of license to permits a software developer to access, run, reuse, modify, combine and share the new software generated by him/her [17, 18].

For sure, the main problems related to software development are: delivery delay; change in initial requirements; bad or incomplete requirements; and difficulties in software maintenance. Depending on the adopted lifecycle, these problems could be attenuated or worsened [19, 20, 21, 22]. Software reuse techniques can reduce costs, effort and time [23]. For instance, by applying component-based software development, it is possible to save costs, time and improve the product quality [24].

Inspired by the open-source foundations, many openness-related movements arose, like OER (Open Educational Resources). According to the Willey [25, 26], OER are driven by five pillars, called of $5 \mathrm{R}$ principles: 
1. Reuse: the possibility of having open access and use

2. Review: the possibility of adapting, translating or modifying any OER

3. Remix: the possibility of combining any OER with another one

4. Redistribute: the possibility of sharing the content

5. Retain: the right to retain indefinitely the original license

According to [17] since the OEGs can be classified as a type of OER, all 5R rights can be applied to them. This is also defended by [18], which considers that such liberties are essential to find, compose, adapt, reuse and share OER, especially OEGs and their components and assets, which would allow reducing costs, efforts and time in their development and reuse.

\subsection{Adaptation and reuse of educational digital games}

The main premise of OER could be resumed as: world's knowledge is a public good and it should be shared through technology so that everyone can use it and reuse it as they wish [18].

A study on the reuse of many different types of software presented in [50] points out that reuse seems to be a rather neglected software engineering technique while developing Open Source Software (OSS) related to game development and game developers seem to pay limited attention to reuse. Also according to [50], such evidence can be valuable to researchers and practitioners as a guide for selecting appropriate projects to study or explore opportunities for reuse.

As we can read in [35], software reuse usually comes in two main forms: planned and opportunistic reuse. The work [36] shows that an organization can have more high levels of productivity and quality if it uses a formalized way to reuse software in a planned and systematic manner. To the work with OER the developers teams, in general, are small groups, because big developer's teams have an expensive cost, so OER developers are more able to use opportunistic forms of software reuse than planned ones.

To use and have an experience with an EG each person will learn in your own rhythm, so it is necessary to adapt and improve by gathering as much information about the learner [31].

About the adaptation in DGs we face two main types: first, the adaptation under the developer's point of view, when the developer wants to adapt his/her game to some different context or specific purpose. Second, the adaptation under player's perspective, when the player wants to adapt the game to let it more customized and to satisfy his/her own preferences.

According to [32]. in general games are highly adaptable for different technologies and contexts, but according to [18] the adoption, reworking/adaptation and sharing of OER has had only limited success, because it appears to exist few evidence of OER reuse and sharing by individual users and specially by teachers. Thus, the reuse and adaptation of EGs need to be deeply investigated under a scientific approach.

According to [32] and [33], learners have different emotional responses to game mechanics; these different responses could cause distinct behaviors and they can be 
illustrated by several players' typologies, which can be used for adaptation. [34] shows only few papers that really success to adapt game dynamics: some of them adapt storytelling, others adapt the quests presented and some others adapt game scenes; this type of adaptation is more related to the second type of adaptation because of the personal factors about the individual responses.

In this paper, we are more interested in the first type of adaptation, which refers to adapting or repurposing the game to another context. In this sense, a valid scenario would be using some commercial game to be adapted to the educational context, offering educational repurposing.

There are tools to facilitate the work of reuse and adaptation on the game development tasks; a common tool to do it is the Game Engine itself. However, many engines are not cost-free, and game studios that acquire this type of software usually have a great cost, cause one year license of high level engine may be priced over several thousands of American dollars.

Nowadays there are some open, cost-free game engines; nonetheless, according to [37] $86 \%$ of the biggest hidden cost in the game development process, is in adapting the engine's code to suit specific games' needs. That is the reason why the most traditional game developers use their own game technology to build their games.

In spite of this, OSS philosophy brings new opportunities to game developers to create, adapt or repurpose EGs not having to start from the scratch. Thus, such principles could serve as a support to break the barriers to reuse and adapt games in the educational context.

\subsection{Related researches}

Below we present some works that are related to the present one.

The authors of [38] explain that DGs have become an important part of the recent generations' lives, being each time more present of the contemporary young culture. There is an increasing interest among the researches and educators in figuring out if DGs are really a powerful new medium to support student's learning in the so-called information age. The paper provides a review of literature on the effects of DGs on students' learning; besides, it shows some barriers and challenges in using DGs within the current educational system, including the high costs and license problems as challenges. The paper affirms that the existing literature has suggested that DGs might be appropriately designed to have a positive impact on students' learning. The authors categorize DGs in edutainment (educational with entertainment elements) and commercial-off-the-shelf (COTS, totally for entertainment). They also say that educators can make use of digital games from any of these two categories to benefit students' learning process by guiding them to reach learning objectives within the game content.

[40] presents a systematic review about educators that are using games in universities to improve learning in traditional classes. They say serious games are used by students to learn programming, reinforcing the knowledge already built in classroom activities. The authors also point out that developing a 'good' game is not an easy task, because it demands time, resources, besides requiring a multidisciplinary team 
that cover programming and graphical design skills. Also in this paper, it is mentioned that its main goal is to identify game elements existing in serious games for learning programming. For this, they have used five scientific databases to select 39 primary studies published between 2007 and 2016. They note that six specific types of games elements were used in majority of the serious games of the research (avatar, fantasy, goal, level, points and quest). Thus, they conclude that no study was found directly evaluating the link between game elements and learning outcomes for learning programming; furthermore, more studies are required to assess the effectiveness of specific game elements in learning process. Still according to the paper, the number of scientific studies involving serious games to learn programming in higher education is low; the majority of online available games are not related to any scientific publication and the scientific community of serious games applied to learn programming need more results published in scientific channels.

In this sense, our systematic review paper about OEG differs from these others papers in some aspects: first, we kept focus on learning and teaching programming skills, to know about reuse and adaptation evidences; second, it was verified if practical works have been used and/or generated open source games as a result; and third, we sought to figure out about trends (in general way) at the current works on OEG.

\section{$3 \quad$ Methodology}

This paper is a survey about OEG to teach and learn programming skills, focusing in adaptation and reuse. The differential of our work is we have analyzed papers about the following topics: if they recommend or implement reuse and adaptation; the trends of scientific research to use and/or generate OEGs; the types/styles of the DGs that are more used to educational purposes; which programming language practitioners and researchers are using in game development; and if there have been reported positive results on usage of OEG.

We limit our survey according to following 5 criteria: (1) it covers the timespan from 2014 to 2019 (5 years and a half); (2) it focuses on studies that dissert about OEGs or similar, being applied research or not; (3) it includes papers published in scientific journals and international conferences and symposia; regional conferences, symposia and workshops were discarded; (4) the papers must be available in full way, thus papers that had only the abstract available were discarded; and (5) the papers had to contain at least two pages; papers with only one page were removed of this review. The selection was made based on the abstracts, introductions and conclusions of each paper (some had only abstracts available);

The literature search was carried out in 2019 April to July, using the following databases: IEEE Xplore Digital Library; ACM Digital Library and Research Gate. The duplicate papers in these sources were not counted. The search string was: Open AND "Educational Games" AND (Program* OR Coding OR "Computational Thinking").

We have found 17 papers with this search string in the three bases, considering the period from 2014 to 2019. 11 of these papers were found at the IEEExplore and 7 others in Research Gate, but one of the papers was repeated, leaving the final count to 
17. The search in ACM brought 12 different papers more, so we had 29 papers in total to be read and analyzed. At this point, we applied our 5 before mentioned search criteria. After this processes, 12 papers were left to compose our review. All selected papers are shown at Table 1.

Table 1. Papers selected for the review

\begin{tabular}{|c|c|c|c|}
\hline \# & Title of the paper & Year & Ref. \\
\hline 1 & An Open Perspective For Educational Games. & 2018 & [17] \\
\hline 2 & $\begin{array}{l}\text { Educational Game "Mengenal Indonesia" as a Medium to Introduce Indonesia to } \\
\text { the Kids. }\end{array}$ & 2019 & [47] \\
\hline 3 & $\begin{array}{l}\text { Online Software Applications for Learning: observations from an Elementary } \\
\text { School. }\end{array}$ & 2014 & [48] \\
\hline 4 & Open Educational Games: Challenges and Perspectives. & 2016 & {$[15]$} \\
\hline 5 & $\begin{array}{l}\text { No-RPG, a Game Interface to Common Core Sequenced Third-Party Educational } \\
\text { Games. }\end{array}$ & 2018 & {$[8]$} \\
\hline 6 & jLegends Online Game to Train programming skills & 2016 & [16] \\
\hline 7 & $\begin{array}{l}\text { An Open Source Framework for Educational Applications Using Cozmo Mobile } \\
\text { Robot. }\end{array}$ & 2018 & [41] \\
\hline 8 & $\begin{array}{l}\text { Using the Kinect Sensor with Open Tools for the Development of Educational } \\
\text { Games for Kids in Pre-School Age. }\end{array}$ & 2015 & [42] \\
\hline 9 & Adventure-Style Game-Based Learning for a Biology Lab. & 2014 & [43] \\
\hline 10 & $\begin{array}{l}\text { Dragon Architect: Open Design Problems for Guided Learning in a Creative } \\
\text { Computational Thinking Sandbox Game. }\end{array}$ & 2017 & [44] \\
\hline 11 & $\begin{array}{l}\text { Developing a Robot Hip-Hop Dance Game to Engage Rural Minorities in Com- } \\
\text { puter Science. }\end{array}$ & 2017 & [45] \\
\hline 12 & From Orlando to Russia: Cross-Cultural Communication Through Gamemaking. & 2016 & [46] \\
\hline
\end{tabular}

\section{$4 \quad$ Results of the Literature Survey}

In a recent (2018) paper, Silveira and Villalba-Condori concludes that the educational games have high cost, much complexity and consists of multidisciplinary content to goals effective usage in classes [17]. The authors relate that openness principles in development and reuse of EGs can bring a new scenario for the multidisciplinary community with possibilities of reusing game assets, platforms, mechanics, narratives and other games artifacts. The paper provides an overview of a framework to assist the development process of OEGs. Such approach could collaborate to improve the effective usage of OEGs. This paper shows a wide general vision about OEGs main characteristics; it does not configure an applied work that uses some EG in a real-world context, since it is based on theoretical studies.

Falahah et al., in a very recent publication (2019) have developed an EG to reinforce and evaluate knowledge about the Indonesian geography [47]. This paper shows an applied research using an EG with some students. The game has been built using a well-known framework called ADDIE, which focuses in five topics: analysis, design, development, implementation and evaluation. The initial goal, which was to develop an EG to teach about Indonesian geography, was reached and the authors alert to the importance of developing a way to facilitate the update and maintenance of the game. 
Authors also show the difficult process of game planning, design and develop (like already cited by [17]). The game was developed using an open-source editor that supports ActionScript language and Android, but the final result of the work was not an open-source game with a free use, nor based on openness principles.

Tay et al., (2014) [48] have made a study about some ICT tools to help learn activities, in particular some EGs. They have applied some EGs in classes of Mathematics, English and Science with support of professors of these courses. The authors had interviewed some teachers to analyze the results; one English teacher said that she had difficulties in selectin the online games to be applied children because she only looked for free, open-source educational games; this could be an indicator that there are few open-source EGs available on the Internet. The authors not developed any game, but they have looked for existent ones to help teachers. The conclusions showed that online educational games could be effectively used to reinforce skills and concepts learned.

In a study of 2016, Silveira does not present any applied study about educational digital games, but presented a paper with a more theoretical emphasis [15]. Maybe the main contribution of this paper is about the barriers faced by the EGs' users, developers and researchers. Such barriers were related to adoption, development, sustainability and innovation. The author points out the expensive costs that usually exist in digital game development, most because of the multidisciplinary team and tools that are required. The low replayability rates observed in educational games are explained by the fact that most users considers them boring; besides, other characteristics are shown as barriers to the EGs usage, explicited by the author. Silveira concludes that digital learning resources development has always been a complex task, in specific the EGs, which are one of the most intricate types of software to be developed. In this sense, the Openness movement brings a completely new scenario for the development of the EGs, according to the author.

Berkling et al., in a 2018 paper, show that is important to motivate the players inside an EG and offer them content under partitioned ways, to force students to try to achieve the goals and move to next part of the game. It requires a good work of game and level design, which can increase the development costs [8]. The project built is called No-RPG because it is based on RPG (Role Playing Game) game style, but not in full sense of the style. This project is offered as open source to be reused in other OEGs - the code is available at GitHub platform. They use JavaScript/JSON to communicate Server and Client side. Authors showed that the results are positives regarding to students' learning outcomes. They conclude that this project is making progress to creating children-friendly, motivational interface to learn the basic skills needed in any society, even when children do not have access to formal schools.

Tsalikidis and Pavlidis, in their 2016 work, point out three approaches to using educational software that stimulates cognitive growth in gamers: building games from the scratch by educators/programmers; integrating commercial games (off-the-shelf); and creating games from the scratch by students [16]. This work has an applied approach, presenting an RPG-based EG (jLegends) built to teach programming to students. To build the game, it were used open-source technologies (Node.js, Phaser, MongoDB and AngularJS) and the Model-View-Controller (MVC) architecture. 
However, the final game does not offer any open-source code as a contribution - the game is free to use, but without open code. This can be seen like a Freedom \#0 of the Free Software Foundation Principles. The authors conclude that there is a lack of EGs to train programming and jLegends game has been developed to help to fill this gap. They present the URL http://jLegends.io to get the game; we have accessed the link, but there were no game available there at the time that this review has been written. This could reinforce the idea that an EG that does not follow the openness principles could be more difficult to maintain when compared to the open-source ones, since no communities are formed around the game.

In a 2018 paper, Kusumota et al. explain as most people learn more easily when they are involved in practical activities, like robotics. On the other hand, there still are some barriers to the adoption of robotics technology in education, the same occurs to EGs. According to the authors, the main barriers are the cost and difficult to use these technologies [41]. The authors have pointed out the possibilities of using software tools to simulate robots to provide educational robotics experiences without the use of a real robot. They have opted to use an open-source, low cost robot called Cozmo, it has an open-source SDK based on Python language; MVC was used as architecture. The authors build some mini-games to teach Mathematical Basic Operations and Geometric Shapes, so players could interact with the robot to try to offer correct answers to Cozmo. The authors conclude that a system with educational functions and games in a robot was developed and is applicable for using in classes, since the programing language used is simple and intuitive. Tests performed with teachers presented positive results and those performed with students also showed positive results.

Fernández and Von-Lucken, in their 2015 paper show an important innovation made to DGs with movement sensor controllers in consoles [42]. These tools were made to videogames consoles to allow player's input by moving his/her body, and the level of innovation was so impressive that new applications emerged out of the consoles. The authors emphasize the emergence of open-source tools to develop for these movement sensors, in particular Microsoft Kinect. In the paper, authors developed an application to be used in educational experiences with pre-school students - the tools used for development were: OpenNI, Ubuntu, C++ language and SFML game development library, all of them open-source. The authors let teachers modify the functionalities of the application, by a XML file, so they can configure the quantity of elements in the game and their images. To evaluate the proposal, an experiment was conducted with 20 children aged between 4 and 5 years old, with 4 professors. The authors conclude that the experiment was very positive and the application was well received by students and professors.

Zafeiropoulos et al., in a 2014 paper, shows that universities and medical companies often face the challenge of develop protective and adaptive tools to train new students or employees in the usage of their laboratories. The equipment inside the laboratories can be sensitive, expensive and sometimes dangerous, in this way it is not affordable for trainees to make improper usage to learn under a trial-and-error approach [43]. In contrast, the authors explain that those learning approaches by reading and writing about educational subjects, helps students to assimilate $10 \%$ of the content while learning by doing is more assertive arriving until $75 \%$ as assimilate rate of 
a content - as shown by classical Bloom's Taxonomy. The authors have made an applied research, developing a 3D adventure game to simulate a biology laboratory. The game was built with Hive3D tool that is a not open-source tool, but it is free to use and to distribute the games built, so we classify it like partially open-source with freedom \#0 (free use), but the authors did not shared their code as open-source. The game was evaluated by 19 Biology students aged form 35 to 50; the evaluation process was based on qualitative research. They conclude that the results of their work were positive and the $3 \mathrm{D}$ game should be expanded to put more laboratorial tools inside the game.

Bauer et al., in 2017, said that generally there are two main types of EGs to teach Computational Thinking: based on open-ended exploration with little direct guidance to students; and based on a linear series of puzzles with lots of direct guidance [44]. Therefore, they opted by use a hybrid approach to study the effectiveness of both. Their work is practical and theoretical, since they developed an educational game (Dragon Architect) to teach Computational Thinking and they have performed a survey research about software systems to teach it. About the different approaches of open-ended against the linear puzzles-based, the authors have made a comparison with two famous commercial games: Legend of Zelda Ocarina of Time by Nintendo studios (an open-ended. non-linear game) and Crusader Kings II by Paradox Development studio (a game with explicit tutorials, providing guidance experience). The 3D game was built with the Three.js library (JavaScript-based) which is open source. Authors conclude that EGs have enormous engaging potential to introduce Computational Thinking features. The educational literature also highlights the need to integrate open-ended exploration with sufficient structured guidance to form a hybrid and balanced approach. Nonetheless, the results not contributed with any open-source code.

Bryant et al., in a 2017 work, discuss details of the development of an EG to be used to engage rural minority middle school students in Computer Science. Authors mention that careers in Science, Technology, Engineering or Mathematics (STEM) are among the fastest growing fields in the world, but statistics show that minority groups are not properly included in STEM studies, which have led to an increasing attentiveness to the need of diversification of these careers [45]. They says that studies showing increased levels of engagement from minority students have incorporated subjects like applied robotics and computer programming in Computer Science classes. The authors decided to develop an EG that used robot hip-hop dancing to engage students. Their work is applied, but still in development phase. Now they are recruiting students to from $7^{\text {th }}$ and $8^{\text {th }}$ grades from rural areas. The game is being developed in HTML5 and JavaScript language and it will be available online to facilitate the access; the authors did not explain if the code will be available as open-source. The paper shows a prototype of game graphical interface and pictures of the robot - they will not use a real robot, but game animations to simulate one.

Kourova, in 2016, showed an educational game to teach languages (in the case, English), in a cross-cultural communication experience, between USA and Russia [46]. The game was developed by American students to teach about the USA and English idiom to Russian students; students that have made use of the game were aged 
from 14 to 18 (thus, belonging to high school). For developing this game, it was used an game development open-source tool called Twine. This tool uses JavaScript combined with HTML5 and CSS; the game use links with text, image and audio resources to teach English language and simulate a travel around the USA. To put audio in Twine tool, they have integrated a third-party audio extension for it. As results, the game was applied to students from a Russian school - authors mentioned that other eleven schools have requested to use the game. The authors commented some testimonial of the students about the game. A very interesting testimonial from a student was: "The most memorable experience was and still is playing together with my American friend. I always think of it when playing it again and again now. We all really miss them."; this comment could indicate that there was probably a replayability of this game. The authors conclude that their most important contribution was offering an insight on how open-source game-based language learning can be adapted to diverse populations. They also affirm that the game would be of special value to other groups, which were not personally involved in their project, that are interested in using it for language learning. However, authors did not mention any action to share their code as an open-source option.

To facilitate the view of some important details about the papers involved in this review, we have made Table II, that shows the main authors, the year of publication, the number of pages, if have used Open Source Tools (OST) and if result in an Open Source Contribution (OSC). In the last column, in gray, there are those works that use and generate open source tools.

We also have analyzed which types of games were more used, which programming languages are most used to build the games and if the works recommend the adoption of reuse and adaptation in OEGs. To facilitate these analyses, we have discarded the sole theoretical works (two of them) and build Table III with the works with an applied approach.

Table 2. Papers used in the review after the discard processe

\begin{tabular}{|c|c|c|l|l|l|}
\hline$\#$ & Reference & Pages & \multicolumn{1}{|c|}{ Type } & \multicolumn{1}{|c|}{ OST Usage } & OSC Result \\
\hline 1 & {$[17]$} & 11 & Theoretical & No & No \\
\hline 2 & {$[47]$} & 10 & Practical & Yes & Yes \\
\hline 3 & {$[48]$} & 26 & Practical & Yes & No \\
\hline 4 & {$[15]$} & 9 & Theoretical & No & No \\
\hline 5 & {$[8]$} & 9 & Practical & Partial & Yes \\
\hline 6 & {$[16]$} & 6 & Practical & Yes & No \\
\hline 7 & {$[41]$} & 8 & Practical & Yes & Yes \\
\hline 8 & {$[42]$} & 12 & Practical & Yes & Partial \\
\hline 9 & {$[43]$} & 5 & Practical & Partial & No \\
\hline 10 & {$[44]$} & 6 & Both (TP) & Yes & No \\
\hline 11 & {$[45]$} & 2 & Practical & Yes & No \\
\hline 12 & {$[46]$} & 8 & Practical & Yes & \\
\hline
\end{tabular}


Table 3. Papers used in the review after the discard processe

\begin{tabular}{|c|c|c|c|c|}
\hline$\#$ & Ref. & Type/Style of Game & $\begin{array}{l}\text { Language of } \\
\text { Development }\end{array}$ & $\begin{array}{c}\text { Reuse and } \\
\text { Adaptation }\end{array}$ \\
\hline 2 & [47] & Quiz & ActionScript & No \\
\hline 3 & [48] & Mix/Undefined & $\begin{array}{l}\text { Mix/ } \\
\text { Undefined }\end{array}$ & Yes \\
\hline 5 & [8] & RPG* & $\begin{array}{l}\text { C\# / } \\
\text { JavaScript }\end{array}$ & Yes \\
\hline 6 & [16] & RPG* & $\begin{array}{l}\text { JavaScript / } \\
\text { HTML5 }\end{array}$ & No \\
\hline 7 & [41] & Mini Games and Simulation* & Python & Yes \\
\hline 8 & {$[42]$} & Mini Games by Gestures & $\mathrm{C}++$ & Yes \\
\hline 9 & {$[43]$} & $\begin{array}{l}\text { Adventure } \\
\text { and Simulation* }\end{array}$ & $\begin{array}{l}\text { HIVE 3D } \\
\text { (No Programming) }\end{array}$ & Yes \\
\hline 10 & {$[44]$} & \begin{tabular}{|l} 
Exploration, \\
Puzzles and RPG*
\end{tabular} & JavaScript / Three.js & No \\
\hline 11 & [45] & Robot Simulation* & JavaScript / HTML5 & No \\
\hline 12 & [46] & Point Click & JavaScript / HTML5 & Yes \\
\hline
\end{tabular}

In Table III, marked with an asterisk, are the most frequent type of games, in bold are the most used programming language and in gray are the reuse and adaptation indication.

\section{Conclusion and Discussion}

We have twelve papers as a result of our systematic review. These papers were obtained after applying our five quality criteria over the primary list of papers extracted from selected scientific databases. Two papers are mainly theoretical, and one other paper is partly theoretical but also presents a practical approach, and the other nine papers are mainly practical, showing the creation, adaptation or use of one or more Educational Games.

We have analyzed the open-source principles adopted for each paper and surprisingly, only two works have used open-source tools in the development and have generated open-source Educational Games as a technical result; and five works have used open-source tools but had not generated any open-source Educational Game as result. In this sense, the majority of researches that says Educational Games should be available in open-source format and recommends the reuse practices in Educational Game Development, do not generate open-source Educational Games, as seen in Table II (in two last columns).

The most frequent types of Educational Games were RPG and simulations; the most used programming language to develop games is JavaScript (with 5 between 10 works); and 6 between 10 works recommend reuse and adaptation in Educational Games development, as in the Table III. 
There is a trend to use RPG or simulation dames, as well as Web-based programming languages, in $2 \mathrm{D}$ or $3 \mathrm{D}$ format, which facilitates the distribution of games in Web and mobile platforms. The majority of the papers recommend the usage of component-based reuse and adaptation, but most of them, do not generate any open-source Educational Game, which converges to the [18] affirmations about the reuse not happening in a practical sense.

According to [40] the number of studies with serious games to learn programming in higher education was low in scientific publications. We agree with them, alerting that the scientific community of serious games to learn programming need more production published in scientific journals and conferences. Thus, even though reuse and adaptation occurs in some situations, these are not being properly documented or shared in scientific channels, which lead us to the need of improvement of researches in this area.

\section{Acknowledgement}

This work was supported by Mackenzie Presbyterian University (UPM) under grant \#509 as a full scholarship for the first author, we want to thank it.

\section{$7 \quad$ References}

[1] Cidrim, L., \& MADEIRO, F. "Information and Communication Technology (ICT) Applied to Dyslexia: Literature Review". CEFAC, Speech, Language, Hearing Sciences and Education Journal, vol. 19, no. 1, p.99-108, 2017. [Online serial]. Available: http://www.scielo.br/scielo.php?pid=S1516-18462017000100099\&script=sci arttext\&tlng =en [Accessed February 12, 2020].

[2] Bagon, S., Gacnik, M., \& Starcic, A. I., "Information and Communication Technology Use Among Students in Inclusive Classrooms". International Journal of Emerging Technologies in Learning, vol. 13, no. 06, p. 56-72, 2018. [Online serial]. Available: https://onlinejournals.org/index.php/i-jet/article/view/8051/4992 [Accessed February 12, 2020]. https:// doi.org/10.3991/ijet.v13i06.8051

[3] Frey, C. B., \& Osborne, M. A., "The Future of Employment: How Susceptible are Jobs to Computerisation?". Technological Forecasting and Social Change, p. 254-280, 2017. https ://doi.org/10.1016/j.techfore.2016.08.019

[4] Kanbul, S., \& Uzunboylu, H., "Importance of Coding Education and Robotic Applications for Achieving 21st-century Skills in North Cyprus". International Journal of Emerging Technologies in Learning, vol. 12, no. 01, p. 130-140, 2017. [Online serial]. Available: https://online-journals.org/index.php/i-jet/article/view/6097/4264 [Accessed February 12, 2020]. https://doi.org/10.3991/ijet.v12i01.6097

[5] Mladenovic, S., Krpan, D., \& Mladenovic, M., "Using Games to Help Novices Embrace Programming: From Elementary to Higher Education”. International Journal of engineering Education, p. 521-531, 2016. https://doi.org/10.21125/edulearn.2016.1323

[6] Gomes, A., \& MENDES, A. J., "Learning to Program - Difficulties and Solutions". International Conference on Engeneering Education, p. 3-7, 2007. 
[7] Baist, A., \& Pamungkas, A. S., "Analysis of Student Difficulties in Computer Programming”. Scientific Journal of Electrical Engineering Education (VOLT), p. 81-92, 2017. https://doi.org/10.30870/volt.v2i2.2211

[8] Berkling, K., Incekara, M. A., \& Wolskw, T., "No-RPG, a game interface to commom core sequenced third-party educational games". IEEE Global Engeneering Education Conference, 1524-1532, 2018. https://doi.org/10.1109/educon.2018.8363414

[9] Repening, A., Basawapatna, A., \& Koh, K. H., "Making University Education More Like Middle School Computer Club: Facilitating the Flow of Inspiration". 14th Western Canadian Conference on Computing Education, p. 9-16, 2009. https://doi.org/10.1145/1536274. 1536281

[10] Hwa, S. P., "Pedagogical Change in Mathematics Learning: Harnessing the Power of Digital Game-Based Learning”. Education Technology e Society, p. 259-276, 2018.

[11] Talingdan, J. A., \& Llanda, C. R., "Assesment of the effectveness of learning theories using gamified android app in teaching C programming". International conference on information technology and digital applications, p. 482-487, 2019. https://doi.org/10.1088/175 $\underline{7-899 x / 482 / 1 / 012030}$

[12] Noemí, P. M., \& Máximo, S. H., Educational Games for Learning. Universal Journal of Educational Research, p. 230-238, 2014.

[13] Hamari, J., Shernoof, D. J., Rowe, E., Coller, B., Asbell-Clarke, J., \& Edwards, T., "Challenging games help students learn: an empirical study on engagement, flow and immersion in game-based learning". Computer in Human Behaviour, p. 170-179, 2016. https://doi. org/10.1016/j.chb.2015.07.045

[14] Wichadee, S., \& Pattanapichet, F., "Enhanced of Performance and Motivation Through Application of Digital Games in an English Language Classrooms". Teaching English With Technology, p. 77-92, 2018.

[15] Silveira, I. F., "Open Educational Games: Challenges and Perspectives". XI Latin America conference on Learning Objects and Technology (LACLO), p. 1-9, 2016. https://doi.org/10. $\underline{1109 / \text { laclo.2016.7751778 }}$

[16] Tsalikids, K., \& Pavlids, G., "jLegends: online game to train programming skills". 7th International conference on Information, Intelligence, systems \& Applications, p. 1-6, 2016. https://doi.org/10.1109/iisa.2016.7785393

[17] Silveira, I. F., \& VILLALBA-CONDORI, K. O., "An Open Perspective for Educational Games". Journal of Information Technology Research (JITR), 18-28, 2018.

[18] Beaven, T., “'Dark reuse': an empirical study of teachers' OER engagement". Open Praxis, p. 377-391, 2018. https://doi.org/10.5944/openpraxis.10.4.889

[19] Sommerville, I., "Software Engineering" (9th Edition). Pearson, Boston, Massachusetts, 2011.

[20] Mansor, Z. B., Razali, R.,; Yahaya, J., Yahya, S., \& Arshad, N. H., "Issues and Challenges of Cost Management in Agile Software Development Projects". Advanced Science Letters, p. 1981-1984, 2016. https://doi.org/10.1166/asl.2016.7752

[21] Pressman, R. S., "Software Engineering: A Practitioner's Approach" (7th edition). McGRaw-Hill, New York, NY, 2011.

[22] Kuutila, M., Mäntylä, M., Farooq, U., \& Claes, M., "Time Pressure in Software Engineering: A Systematic Literature Review". arXiv:1901.05771, 30 pages, 2019.

[23] Alfakhry, A. Z., \& Hasoon, S. O., "Expert System for Software Reusability". International Journal of Computer Applications Foundation of Computer Science (FCS), NY, USA, p. 39-47, 2018. 
[24] Murthy, B. V. R., Padmakar, V., \& Vasavi, A., "Software Reuse - Changes In Process And Organizations". International Journal of Advanced Research in computer Science, p. 154-158, 2014.

[25] Wiley, D. A., "The access compromise and the 5th R", 2014. [online] Accessed November 17, 2019. http://opencontent.org/blog/archives/3221.

[26] Wiley, D.; \& Green, E. D., "Why Openness in Education?" in Game Changers: Education and Information Technologies, 2012. Louisville:Educause, p. 81-89, 2012.

[27] AlShaiji, O. A., "Video Games Promote Saudi Kids. English Vocabulary Retention". Asia Pacific Journal of Contemporary Education and Communication Technology (APJCECT), p. 315-324, 2017.

[28] Reese, D. D., Tabachnick, B. G., \& Kosko, R. E., "Video game learning dynamics: Actionable measures of multidimensional learning trajectories". British Journal of Educational Technology, p. 98-122, 2015. https://doi.org/10.1111/bjet.12128

[29] Taghizadeh, M., Vaezi, S., \& Ravan, M., "Digital Games, Songs and Flashcards and their Effects on Vocabulary Knowledge of Iranian Preschoolers". International journal of English language \& translations studies, p. 156-171, 2018.

[30] Risnawati, Z. A., \& Wahyuningsih, D., "The Development of Educational Game as Instructional Media to Facilitate Students' Capabilities in Mathematical Problem Solving”. 2nd International Conference on Statistics, Mathematics, Teaching, and Research IOP Publishing, p. 1028-1035, 2018. https://doi.org/10.1088/1742-6596/1028/1/012130

[31] Boufera, H., Bendella, F., \& Sehaba, K., "Development of an Adaptive Collaborative Serious Game Based on Learning Style, Using Trace and Agent Technology". Journal of Digital Information Management, p. 127-135, 2018. https://doi.org/10.6025/jdim/2018/16/3/ $\underline{127-135}$

[32] Lavoué, E., Monterrat, B., \& Desmarais, M., “Adaptive Gamification for Learning Environments". IEEE Transactions On Learning Technologies, 16-28, 2018. https://doi. org/10.1109/tlt.2018.2823710

[33] Gläser-Zikuda, M., Stuchlikova, I., \& Janik, T., "Emotional Aspects of Learning and Teaching: Reviewing the Field - Discussing the Issues". Orbis Scholae Theoretical And Research Papers, p. 7-22, 2013. https://doi.org/10.14712/23363177.2015.18

[34] Nacke, L. E., Bateman, C., \& Mandryk, R. L., "BrainHex: A neurobiological gamer typology survey". 10th International Conference on Entertainment Computing, 55-62, 2014. https://doi.org/10.1016/j.entcom.2013.06.002

[35] Lambropoulos, A., Ampatzoglou, A., Bibi, S., Chatzigeorgiou, A., \& Stamelos, I., "REACT - A Process for Improving Open-Source Software Reuse". 11th International Conference on the Quality of Information and Communications Technology (QUATIC' 18)At: Coimbra, Portugal, p. 251-254, 2018. https://doi.org/10.1109/quatic.2018.00044

[36] Ajila, S. A., \& Wu, D., "Empirical study of the effects of open source adoption on software development economics". Journal of Systems and Software, 1517-152, 2007. https:// doi.org/10.1016/j.jss.2007.01.011

[37] Nemitz, W., "Cristina: A tool for refactoring source codes of game prototypes into reusable codebases". Proceedings of SBGames, p. 18-25, 2016.

[38] Mahali, M., Jamaluddin, J., Din, N. M., Faizan, A., Jabar; F., Fadzillah, N. S. M., Fadzillah, M., \& Ahmad, M. A. N., "The Effects of Digital Games on Student's Learning Experience: A Review of Literature". Conference: Konferensi Akademik KONAKA 2016 At: UiTM PahangVolume: 2016, p. 212-215, 2016.

[39] Utoyo, A. W., "Video Games as Tools for Education". Conference: Journal of Game, Game Art, and Gamification (JGGAG)At: Jakarta, Indonesia, 56-60, 2018. 
[40] Santos, A. L., Souza, M. R. A., Figueiredo, E., Dayrell, M., "Game Elements for Learning Programming: A Mapping Study". Proceedings of the 10th International Conference on Computer Supported Education (CSEDU 2018), p. 89-101, 2018. https://doi.org/10.1007/ 978-3-030-21151-6 17

[41] Kusumota, V., Aroca, R., V., \& Martins, F., “An Open Source Framework for Educational Applications Using Cozmo Mobile Robot". Latin American Robotic Symposium, 569-576, 2018. https://doi.org/10.1109/lars/sbr/wre.2018.00104

[42] Romina, F., \& Lücken, C. V., "Using the Kinect sensor with open source tools for the development of educational games for kids in pre-school age". Conferencia Latinoamericana En Informatica (CLEI), p. 1-12, 2015. https://doi.org/10.1109/clei.2015.7360041

[43] Zafeiropoulos, V., Kalles, D., \& Sgourou, A., “Adventure-Style Game-Based Learning for a Biology Lab". International Conference on Advanced Learning Technologies (IWALT), p. 665-667, 2014. https://doi.org/10.1109/icalt.2014.195

[44] Bauer, A., Butler, E., \& Popović, Z., "Dragon architect: open design problems for guided learning in a creative computational thinking sandbox game". FDG'17 Proceedings of the 12th International Conference on the Foundations of Digital Games, p. 14-20, 2017. https ://doi.org/10.1145/3102071.3102106

[45] Bryant, D. G., Liles, K. R., \& Beer, J. M., "Developing a Robot Hip-Hop Dance Game to Engage Rural Minorities in Computer Science". HRI '17 Proceedings of the Companion of the 2017 ACM/IEEE International Conference on Human-Robot Interaction, p. 89-90, 2017. https://doi.org/10.1145/3029798.3038358

[46] Kourova, A., Salter, A., Pidberejna, I., \& McDaniel, R., "From Orlando to Russia: CrossCultural Communication through Gamemaking". Proceedings of the 34th ACM International Conference on the Design of Communication, p. 1-8, 2016. https://doi.org/ $\underline{10.1145 / 2987592.2987600}$

[47] Falahah, \& Irrahali, F. A., 'Educational Game 'Mengenal Indonesia' as a Medium to Introduce Indonesia to the Kids". International Journal of Higher Education, p. 47-56, 2019. https://doi.org/10.5430/ijhe.v8n3p47

[48] Tay, L.Y., Lim, C. P., Nair, S. S., \& Lim, S. K., "Online software applications for learning: observations from an elementary school”. Journal Educational Media International, p. 146-161, 2014. https://doi.org/10.1080/09523987.2014.924663

[49] Albert A., P., "Digital Games -A Magical Learning Tool For Slow Learners". International Journal of Research - Granthaalayah, p. 407-412, 2018.

[50] Maria-Eleni, P., Ampatzogloua, A., Bibi, S., Chatzigeorgiouc, A., \& Stamelos, I., "Reusability of open source software across domains: A case study". The Journal of Systems and Software 134 (2017), p. 211-227, 2017. https://doi.org/10.1016/j.jss.2017.0 $\underline{9.009}$

\section{Authors}

Josivan Pereira da Silva received the BSc degree in Computer Science from Cruzeiro do Sul University, Sao Paulo, SP, Brazil (2008) and MSc degree in Information Engineering from Federal University of ABC, Santo Andre, SP, Brazil (2016). Currently pursuing a $\mathrm{PhD}$ at Mackenzie University; and teaching at Cruzeiro do Sul University in Computer Science, Analysis and Development of Systems and Digital Games courses and also at Faculty of Technology Impacta in Digital Games course (Sao Paulo, Brazil). 
Ismar Frango Silveira holds a BSc degree in Mathematics and Computer Science from the Federal University of Juiz de Fora (1994), Brazil; a Master's degree in Sciences (Computer Graphics) by the Technological Institute of Aeronautics (1997), Brazil and a PhD in Electrical Engineering (theme: Distributed Virtual Reality applied to Education) by University of São Paulo (2003), Brazil. He is currently teaches in Universidade Presbiteriana Mackenzie, working in the undergraduate courses of the Faculty of Computing and Computer Science and the Master's and Doctoral Program in Electrical Engineering and Computing; and also at Cruzeiro do Sul University, where he coordinates the Bachelor's Degree in Computer Science and works in the Master's Programs (Professional and Academic) and Doctorate in Science and Mathematics Teaching. He has experience in Computer Science, with emphasis in Informatics in Education, Digital Games, Open Educational Resources, Computational Thinking, Software Engineering and Graphic Processing.

Article submitted 2019-11-19. Resubmitted 2020-02-12. Final acceptance 2020-02-13. Final version published as submitted by the authors. 